\title{
NSR\&D Program Fiscal Year (FY) 2015 Call for Proposals Mitigation of Seismic Risk at Nuclear Facilities using Seismic Isolation
}

Justin Coleman

February 2015

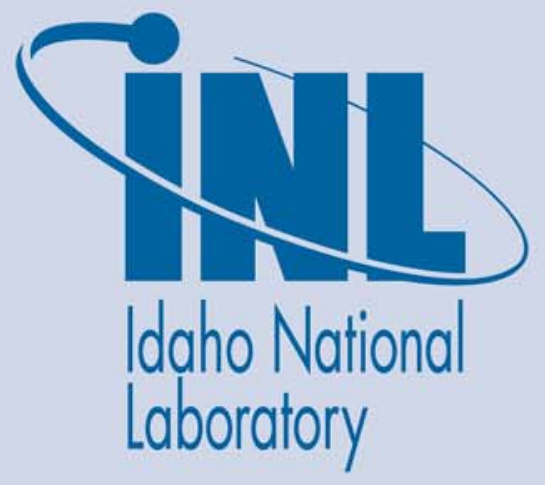

The INL is a U.S. Department of Energy National Laboratory operated by Battelle Energy Alliance 


\title{
NSR\&D Program Fiscal Year (FY) 2015 Call for Proposals Mitigation of Seismic Risk at Nuclear Facilities using Seismic Isolation
}

\author{
Justin Coleman
}

February 2015

\author{
Idaho National Laboratory \\ Idaho Falls, Idaho 83415
}

http://www.inl.gov

Prepared for the

U.S. Department of Energy

Office of Nuclear Energy

Under DOE Idaho Operations Office

Contract DE-AC07-05ID14517 


\section{NSR\&D Program Fiscal Year (FY) 2015 Call for Proposals}

Mitigation of Seismic Risk at Nuclear Facilities using Seismic Isolation

Idaho National Laboratory

U.S. Department of Energy

Office of Nuclear Energy

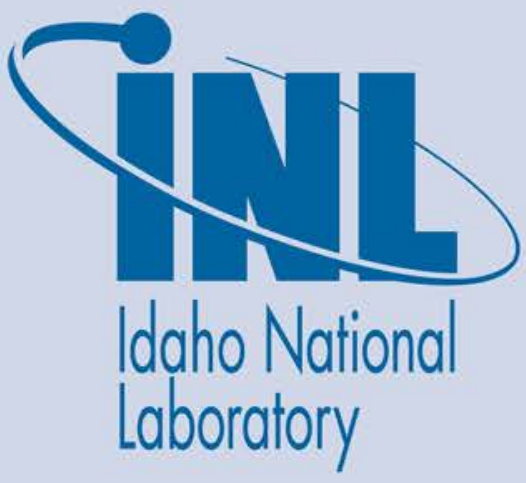

Project Lead: Idaho National Laboratory (INL), Justin Coleman, justin.coleman@inl.gov (208) 526-4741, (208) 251-1767

In Collaboration with: University at Buffalo, Andrew Whittaker, Professor and Chair, Department of Civil, Structural and Environmental Engineering

February $27^{\text {th }} 2015$ 


\begin{abstract}
Seismic isolation (SI) has the potential to drastically reduce seismic response of structures, systems, or components (SSCs) and therefore the risk associated with large seismic events (large seismic event could be defined as the design basis earthquake (DBE) and/or the beyond design basis earthquake (BDBE) depending on the site location). This would correspond to a potential increase in nuclear safety by minimizing the structural response and thus minimizing the risk of material release during large seismic events that have uncertainty associated with their magnitude and frequency. The national consensus standard America Society of Civil Engineers (ASCE) Standard 4, Seismic Analysis of Safety Related Nuclear Structures recently incorporated language and commentary for seismically isolating a large light water reactor or similar large nuclear structure. Some potential benefits of SI are: 1) substantially decoupling the SSC from the earthquake hazard thus decreasing risk of material release during large earthquakes, 2) cost savings for the facility and/or equipment, and 3) applicability to both nuclear (current and next generation) and high hazard non-nuclear facilities.
\end{abstract}

Issue: To date no one has evaluated how the benefit of seismic risk reduction reduces cost to construct a nuclear facility.

Objective: Use seismic probabilistic risk assessment (SPRA) to evaluate the reduction in seismic risk and estimate potential cost savings of seismic isolation of a generic nuclear facility. This project would leverage ongoing Idaho National Laboratory (INL) activities that are developing advanced (SPRA) methods using Nonlinear Soil-Structure Interaction (NLSSI) analysis.

Technical Approach: The proposed study is intended to obtain an estimate on the reduction in seismic risk and construction cost that might be achieved by seismically isolating a nuclear facility. The nuclear facility is a representative pressurized water reactor building nuclear power plant (NPP) structure.

Figure 1: Project activities

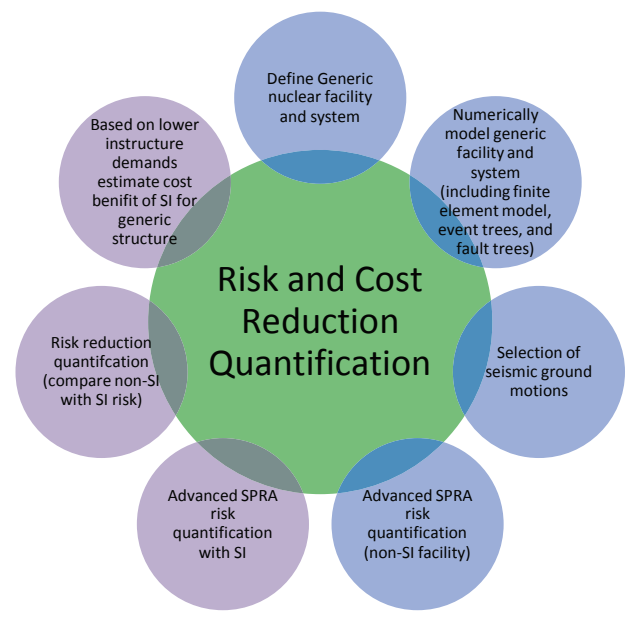

The study will consider a representative NPP reinforced concrete reactor building and representative plant safety system. This study will leverage existing research and development (R\&D) activities at INL. Figure 1 shows the proposed study steps with the steps in blue representing activities already funded at INL and the steps in purple the activities that would be funded under this proposal. 
The following results will be documented: 1) Comparison of seismic risk for the non-seismically isolated (non-SI) and seismically isolated (SI) NPP, and 2) an estimate of construction cost savings when implementing SI at the site of the generic NPP.

Benefits: This research would show the potential reduction in seismic risk and cost of a generic nuclear facility. DOE EM, NNSA, and NE are constructing, planning to construct, or planning to be involve in the construction process of a number of new nuclear facilities (such as CMRR), including Consolidated Storage Facilities, high-level waste facilities, and Small Modular Reactors SMRs. To assist with implementation of seismic isolation (SI) within the DOE complex it is important to understand the potential for SI to minimize risk associated with large ground motions, and reduce the cost of construction.

Implementation of seismic isolation in DOE nuclear facility designs will potentially lead to cost savings in design, system qualification, and construction, decouple the nuclear facility motion from the uncertain seismic hazard, and provide substantial improvements in safety and reductions in risk. 


\section{Introduction:}

\section{Purpose}

Seismic isolation (SI) has the potential to drastically reduce seismic response of structures, systems, or components (SSCs) and therefore the risk associated with large seismic events. This would correspond to a potential increase in nuclear safety by minimizing structural response and thus minimizing the risk of material release during large seismic events that have uncertainty associated with their magnitude and frequency. The national consensus standard America Society of Civil Engineers (ASCE) Standard 4, Seismic Analysis of Safety Related Nuclear Structures has recently incorporated language and commentary for seismically isolating a large light water reactor or similar large building structure. Some potential benefits of SI are: 1) decoupling the SSC from the earthquake hazard thus decreasing risk of material release during large earthquake events, 2) reducing the seismic demand in the design of the facility and/or equipment, and 3) applicability to both nuclear and high hazard non-nuclear facilities. The proposed research of a SI nuclear facility would provide important information on its viability for reducing earthquake risk at Department of Energy (DOE) nuclear and high hazard non-nuclear facilities.

\section{Background}

Idaho National Laboratory (INL) convened a working meeting on August $19^{\text {th }} 2014$ to discuss the current state of SI for nuclear facilities in the U.S. and to discuss the current state, challenges and gaps associated with implementation of SI at NPP's in the US. The meeting included participation from DOE/NNSA, DOE-AU, DOE-NE, EPRI, NRC, LANL, ORNL, TerraPower, Westinghouse, and universities.

The main objective of this working meeting was to discuss the current state and need for seismic isolation for nuclear rectors (structures, systems, and components) and identify the challenges and gaps (Coleman and Sabharwall 2014).

One of the critical gaps identified in the meeting was a cost-benefit analysis of seismic isolation for an entire Nuclear Power Plant or nuclear facility. The gap analysis is provided below:

\section{Cost Benefit (Economic Viability) for SI of an Entire Nuclear Plant}

To our knowledge no one has performed a cost-benefit analysis in the U.S. on an isolated versus non-isolated nuclear systems and components. A cost-benefit analysis would provide valuable insight for DOE and nuclear vendors interested in application of seismic isolation to manage seismic risk in their nuclear facilities.

\section{Importance to DOE and Industry}

Provides DOE and industry with information on potential costs and savings when seismic isolation is implemented in new nuclear facility design and/or modification of existing nuclear facilities.

\section{Current State of Knowledge}

Limited

\section{Current Research and Development}

Limited

\section{Need}

High 


\section{Industry Support for Seismic Isolation}

Due to the potential to reduce the effects of earthquake loadings on SSCs and thus reduce seismic risk, the nuclear industry has already demonstrated a willingness to participate in seismic isolation research.

TerraPower, LLC is participating with the INL and MCEER/University at Buffalo through a Cooperative Research and Development Agreement (CRADA) to develop an industry acceptable methodology for evaluating the potential benefits of seismic isolation of suspended systems. The focus here is to couple a NonLinear Soil-Structure Interaction (NLSSI) methodology with advanced numerical models of seismic isolators. This methodology is currently being developed at INL with funding provided by Department of Energy (DOE) National Nuclear Security Administration (NNSA).

The US NRC is funding research at the Lawrence Berkeley National Laboratory and MCEER/University at Buffalo on the seismic isolation of large LWRs. This research project has supported the writing of the seismic isolation NUREG and the development of advanced numerical models for elastomeric and sliding base isolators (Kumar et al. 2014a, 2014b) that were verified and validated using ASME standards.

Additionally, NuScale has expressed interest in participating in a program that develops a family of seismic isolation solutions for systems and/or components at nuclear facilities. Methods and tools for evaluating the performance of seismic isolation systems for systems and components as well as SI technologies would be documented in a consensus code standard.

\section{Scope}

The proposed study is intended to obtain an estimate on the reduction in seismic risk and construction cost that might be achieved by seismically isolating a nuclear facility. A preliminary study by Huang et al (2009) for an isolated NPP in the Eastern United States, with a representative set of safety-related components, showed dramatic reductions in seismic risk and that study would form a basis for this study. The nuclear facility proposed here is a representative pressurized water reactor building nuclear power plant (NPP) structure of the type constructed in the United States. (The Huang et al. study addressed the CANDU reactor that is not deployed in the United States at this time.)

The study will consider a representative NPP reinforced concrete reactor building and representative plant safety system. This study will leverage existing research and development (R\&D) activities at INL.

- The existing R\&D activities have already accomplished the following:

- Defined generic nuclear facility and system

- Numerically modeled generic facility and system (including finite element model, event trees, and fault trees)

- $\quad$ Selected seismic ground motions

- Performed advanced SPRA risk quantification of a non-SI nuclear facility

- This proposal will fund the following activities

- Advanced SPRA risk quantification with SI

- This includes performing the modeling and simulation runs to determine structural response, developing system fragilities, and performing the systems analysis

- $\quad$ Risk reduction quantification (compare non-SI with SI risk)

- Based on lower in structure demands estimate cost benefit of SI for generic structure

The following results will be documented: 1) Statements of the seismic risk for the non-seismically isolated (non-SI) and seismically isolated (SI) NPP, and 2) an estimate of the construction cost for the conventional and isolated NPP and also cost of the components in the isolated and non-isolated structures. 


\section{Linkage}

Figure 2 shows the linkage from DOE orders to the ASCE-4 Technical Standard that will drive the research effort.

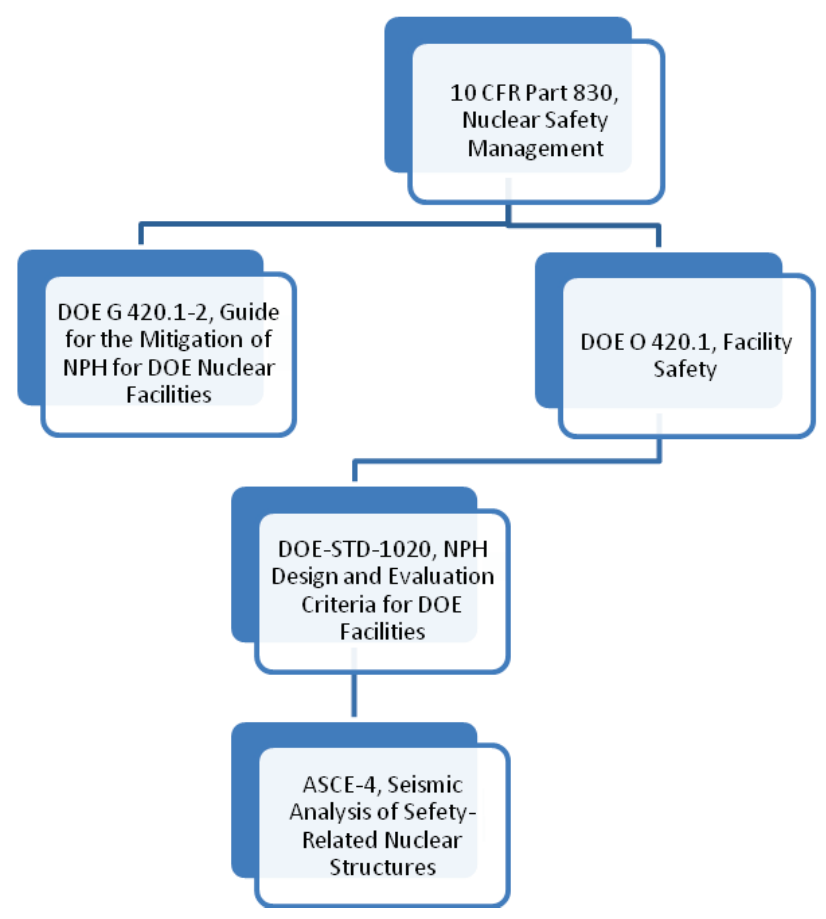

Figure 2 : Linkage between DOE Order and ASCE-4

\section{Business Case}

The updated ASCE-4 standard will allow for seismic isolation of nuclear facilities. Seismically isolated structures have potential to minimize risk associated with large earthquakes. SI also has the potential to decrease the cost of construction through a substantial reduction in the required robustness of the structures, systems and components. With the large investment that DOE is making in nuclear facilities (DOE-EM and DOE/NNSA) and investments in new nuclear builds (DOE-NE programs such as Light Water Reactor Sustainability (LWRS) and Small Modular Reactors (SMR)) in the next 10 years, the cost savings realized from base isolation could be significant. 


\section{Technical Description Section:}

\section{Background}

Seismic isolation has the potential to reduce horizontal earthquake loads for nuclear structures and their components. A substantial reduction in horizontal earthquake loading has the potential to increase the safety of nuclear SSCs by managing the risk associated with large seismic events (Huang et al. 2008). Recent earthquakes near nuclear power plants, Kashiwazaki-Kariwa (2007 Japan), Fukushima (2011 Japan), and North Anna (2011 US), have exceeded their design basis earthquakes (DBE) demonstrating the difficulty in predicting site ground motion. SI has the potential to significantly de-couple the nuclear facility from the earthquake hazard, thus substantially decreasing the risk from a BDBE. There is also the potential to reduce construction cost, and equipment qualification cost associated with seismic events.

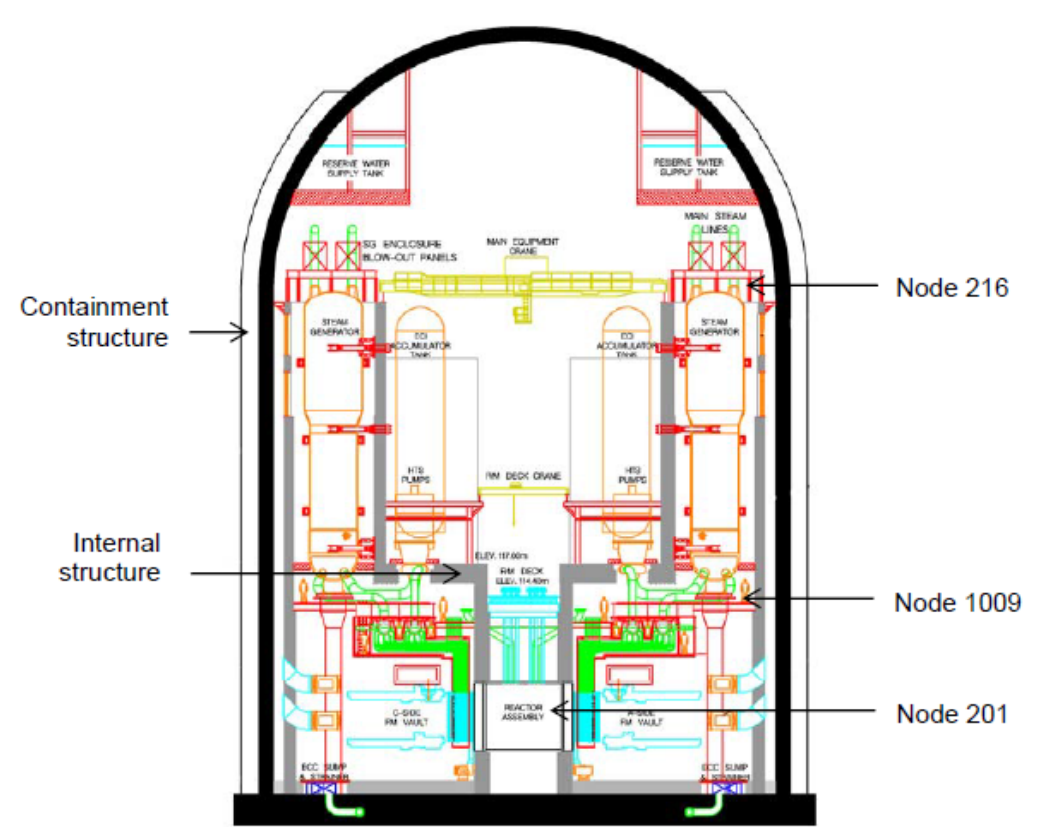

a. a cutaway view of the sample NPP reactor building

Figure 3 : Sample NPP (Huang et al, 2008) 
A computational study of the potential reduction in seismic motion of a sample nuclear power plant (NPP) was performed by Huang et al. (2008). Figure 3 shows the sample NPP. Figure 4 shows the computed reduction of in-structure acceleration due to a design basis seismic event at an East Coast rock site. Model 1 is not isolated and Models 2-4 have different 2-second isolation systems as indicated in

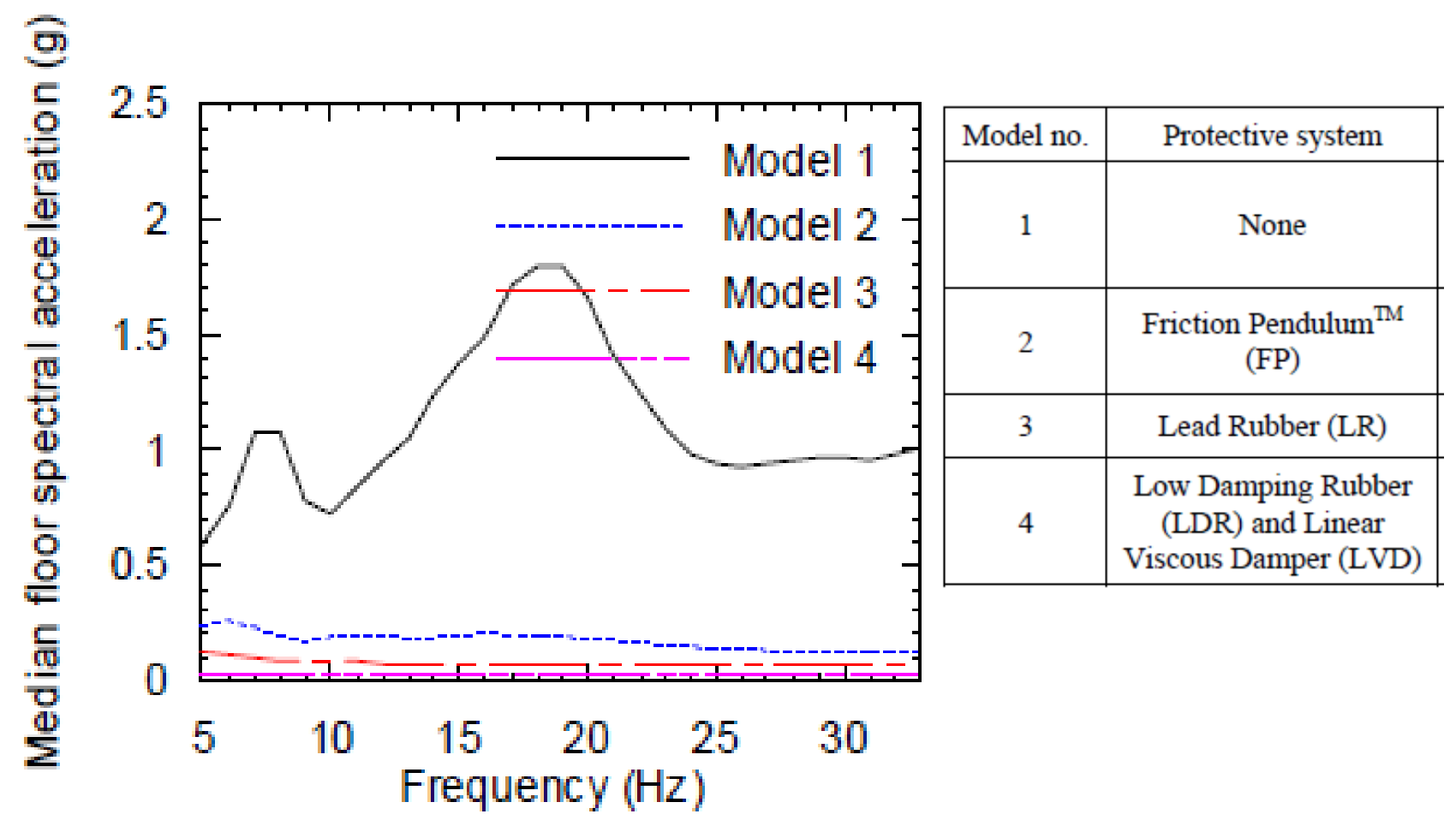

\section{a. Median floor spectral accelerations, Node 201}

Figure 4 : Non-isolated NPP (Model 1) versus isolated NPP (Model 2)

SI has been used for years in the non-nuclear commercial industry including buildings, bridges, liquid gas tanks, and offshore oil and gas platforms. However SI of nuclear facilities, nuclear power plants (NPP), and their systems and components is a relatively new concept in the United States and an investigation is needed to determine the potential to manage risk, reduce uncertainty, and increase safety. NRC is in the process of publishing a NUREG that will be the first document released by the US Nuclear Regulatory Commission (NRC) that provides information on SI of nuclear power plants, with a focus on large light water reactors. Also Section 7.7 of the forthcoming revised ASCE 4 standard provides detailed guidance on the seismic isolation of safety-related nuclear structures with the intent of achieving seismic performance much better than conventional nuclear structures. The lead author of the NUREG and Section 7.7 of ASCE 4 is participating in this project.

\section{Proposed Project}

The proposed one-year study is intended to obtain an estimate of the reduction in seismic risk and the difference in construction cost that might be achieved by seismically isolating a nuclear facility. The nuclear facility is a representative pressurized water reactor building nuclear power plant (NPP) structure.

The study will consider a representative NPP reinforced concrete reactor building and representative plant safety system. This study will leverage existing research and development (R\&D) activities at INL. 


\section{Existing INL R\&D Activities (Funding already provided)}

This initial study is intended to obtain a first estimate on the potential reduction in seismic risk that might be achieved by Nonlinear Soil-Structure Interaction (NLSSI) analysis relative to the seismic risk obtained by a traditional SPRA. The uses a representative NPP reinforced concrete reactor building and representative plant safety system (Coleman 2014).

\section{Defined generic nuclear facility and system}

The selected representative NPP structure is a pressurized water reactor building example obtained from the SASSI2000 User Manual. It consists of a prestressed concrete containment structure and reinforced concrete internal structure. The structure is shown in Figure 5.

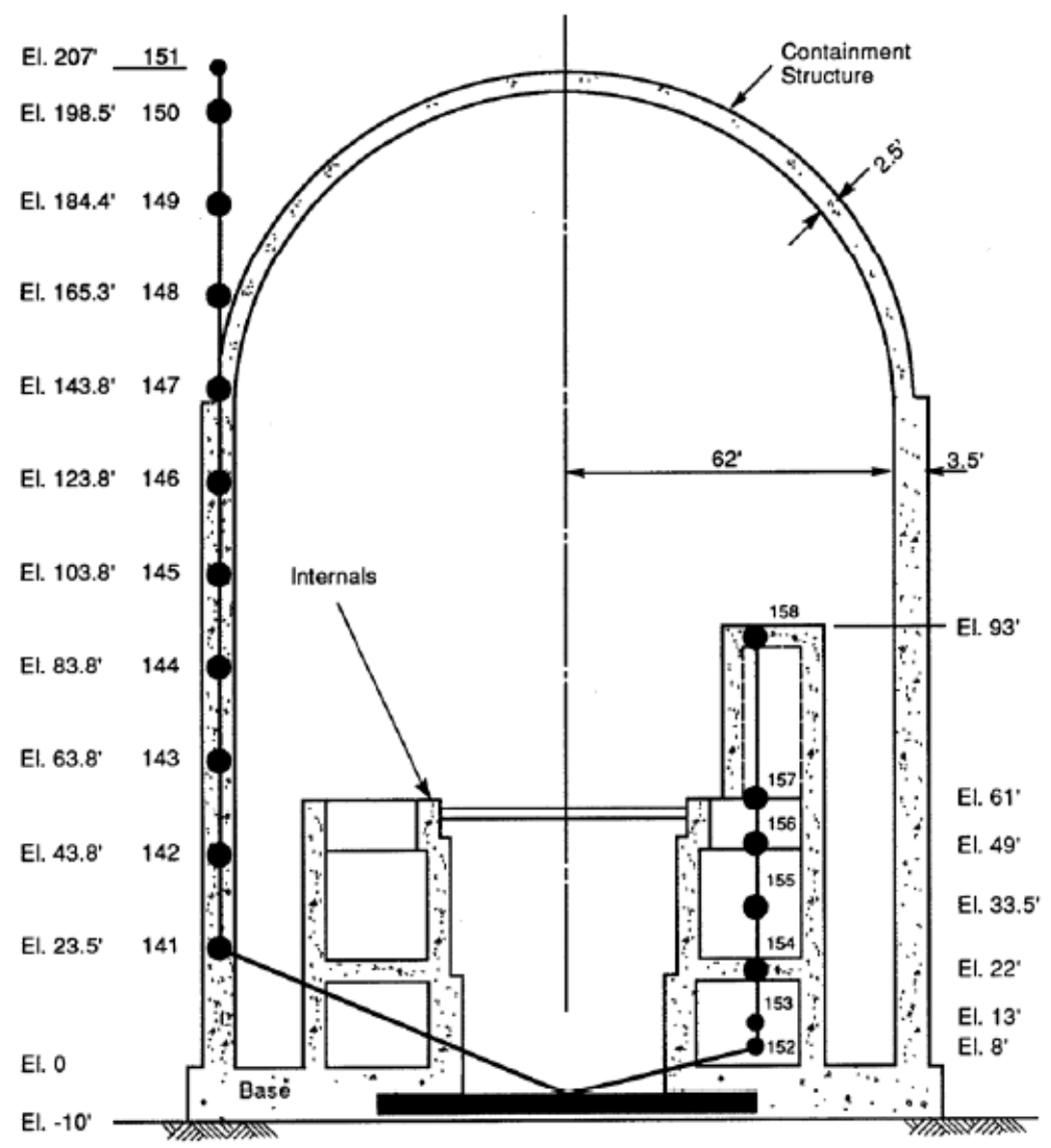

Figure 5 - Stick Model of the Representative NPP Structure

The plant system is an Emergency Cooling Pump. The pump has an electric motor that is powered by Battery. The motor is started by associated control logic. The system consists of the following components:

- Emergency Cooling Pump (Figure 6)

- Battery (Figure 7)

- Distribution Panel; Circuit Breakers 
- Low Voltage Switchgear; Relay

- Medium Voltage Switchgear; Primary Pump Relay

- Flow Indicator Switch

- Concrete Block Wall.

The plant system components are all located on the internal structure. Emergency Cooling Pump and Medium Voltage Switchgear are located at Elevation $22 \mathrm{ft}$. The remaining system components are located at Elevation $61 \mathrm{ft}$.

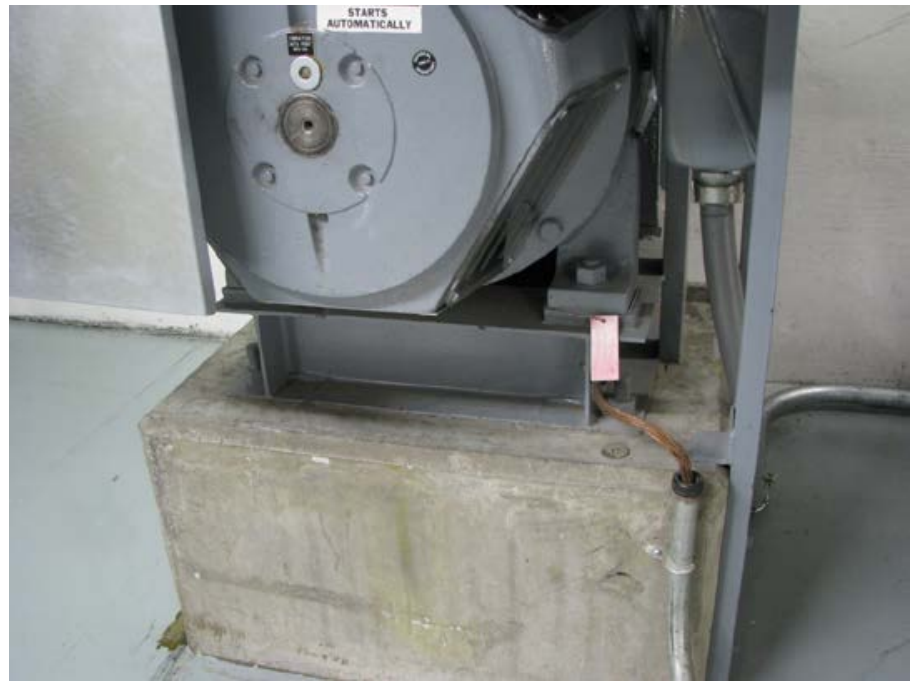

Figure 6 - Emergency Cooling Pump

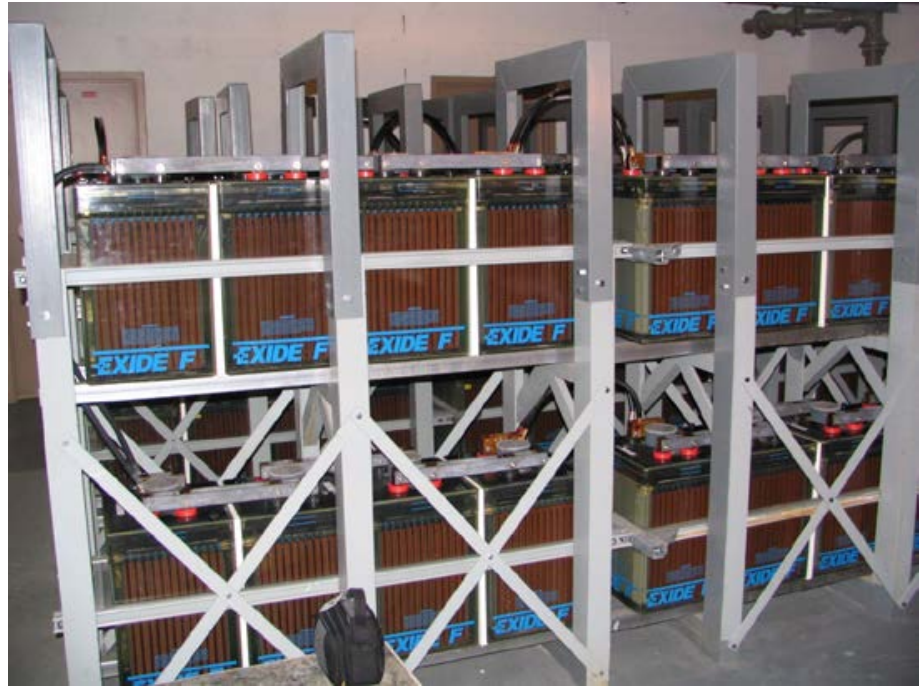

Figure 7 - Battery

\section{Selected seismic ground motions}

The earthquake ground motion used is based on the seismic hazard for an existing NPP. Figure 8 shows the seismic hazard curve expressed in terms of the horizontal peak ground acceleration (PGA) and 
associated mean annual frequency of exceedance (MAFE). However for this study it is likely that the hazard and fragility curves will be presented in terms of a parameter other than PGA.

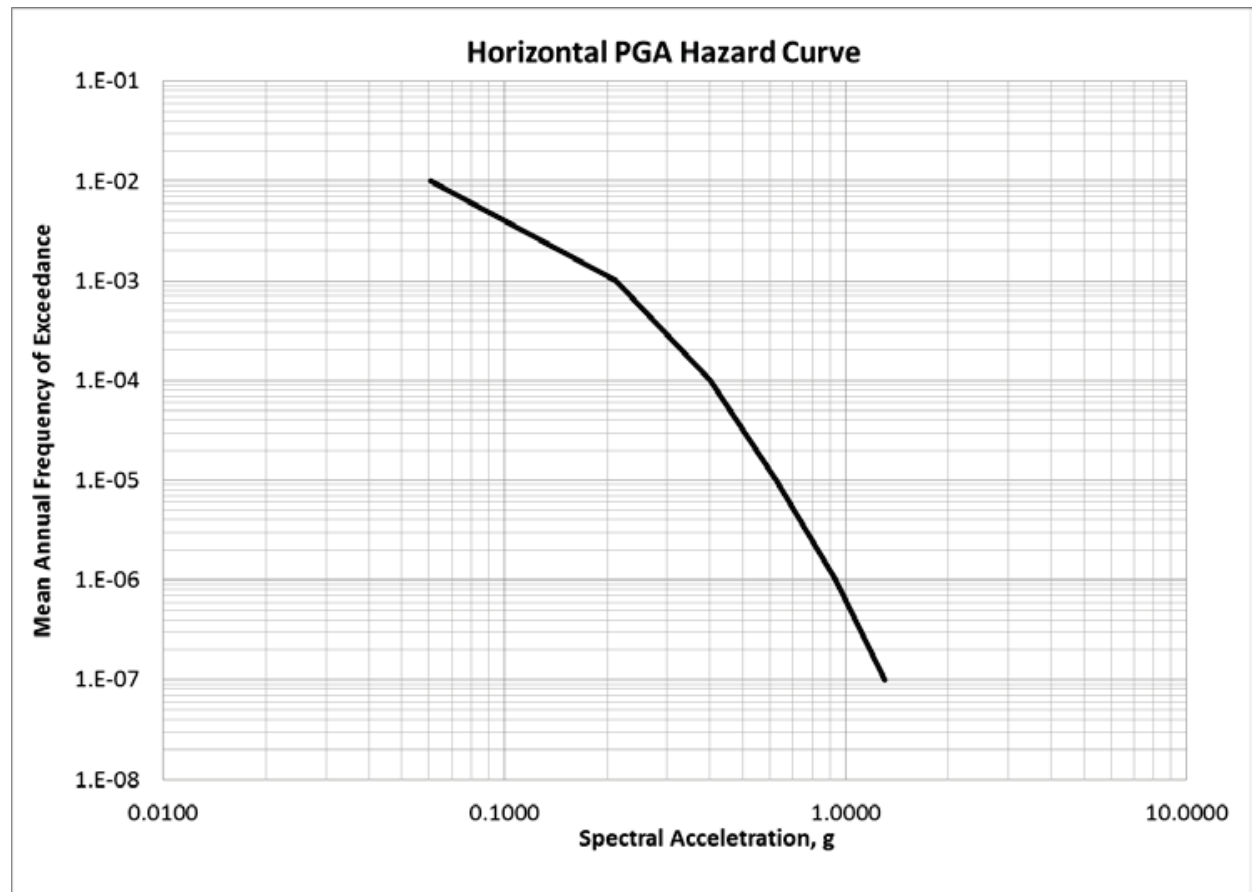

Figure 8 - Seismic Hazard Curve for Horizontal PGA

\section{Proposed INL R\&D Activities (Activities this proposal will fund)}

This proposal will leverage the above R\&D activities by using the NPP structures and systems, systems model, and seismic hazard curve developed above. This proposal will fund the following activities.

\section{Advanced SPRA risk quantification with SI}

A seismic isolation system will be placed under the NPP basemat shown in Figure 5. INL and University at Buffalo (UB) will use post-doctoral and graduate students to performing the modeling and simulation runs to determine structural response, develop system fragilities, and performing the systems analysis.

INL and UB will quantify the risk reduction by comparing the non-SI NPP risk (developed using other funding) with SI risk. Based on lower in-structure response to the same seismic hazard curve INL and UB will estimate reduction in concrete, rebar, and anchorage requirements. INL will also estimate the cost of the SI system.

\section{Drivers:}

DOE EM, NNSA, and NE are constructing, planning to construct, or planning to be involve in the construction process of a number of new nuclear facilities, including Consolidated Storage Facilities, high-level waste, and Small Modular Reactors SMRs. With the potential for seismic isolation systems to minimize risk at nuclear facilities associated with large ground motions, and also potentially reduce the cost of construction, it is necessary to understand the potential cliff edge effects associated with hitting the moat or hard stop during BDBE. 


\section{Project Tasks and Deliverables:}

Monthly status reports, bi-annual presentations, and a final report will be provided during the project period, FY2015 (These deliverables a detailed in Figure 9). A more detailed list of tasks is provided in Figure 10 below.

\begin{tabular}{|l|l|l|l|l|}
\hline FY 2015 Milestones & Quarter 1 & Quarter 2 & Quarter 3 & Quarter 4 \\
\hline Task & & & & \\
\hline Monthly Status Reports (email) & & & & \\
\hline Bi-Annual Presentation & & & & \\
\hline Final Report & & & & \\
\hline
\end{tabular}

Figure 9: Project Deliverables by Quarter

\begin{tabular}{|l|l|l|r||r|}
\hline FY2015 & & & & \\
\hline Task & Quarter 1 & Quarter 2 & Quarter 3 & Quarter 4 \\
\hline Implement SI model into NPP & & & & COST \\
\hline Make model runs and gather data & & & & $\$ 16,000$ \\
\hline Perform SPRA risk quantification & & & & $\$ 40,000$ \\
\hline $\begin{array}{l}\text { Estimate cost of SI system and estimate cost } \\
\text { savings of reduction in construction materials }\end{array}$ & & & & $\$ 40,000$ \\
\hline Write report and Journal Article & & & & \\
\hline Peer Review Report & & & & $\$ 50,000$ \\
\hline Administrative and Project Management Costs & & & & $\$ 29,000$ \\
\hline TOTAL FY 2015 & & & & $\$ 19,000$ \\
\hline
\end{tabular}

Figure 10: Project task break down by quarter

\section{Anticipated Funding Requirements:}

This study requires approximately $\$ 235,000$ for FY2015. Seismic isolation of nuclear facilities is a new application of a proven technology.

Project Interfaces/Participants: The Idaho National Laboratory will collaborate with University at Buffalo on this study. The Buffalo team, led by Professor Andrew Whittaker, brings unparalleled expertise in the field of seismic isolation, with $25+$ years of experience in development and testing of isolation and damping devices, hysteretic models of isolators, numerical models for isolators, computer codes for analysis of isolation systems, regulatory guidance for analysis, design and testing of seismic isolation systems, and experience in modeling beyond nuclear structures for beyond design basis loadings, including air blast and ground shock. Dr. Whittaker has worked on joint projects related to seismic isolation of mission-critical structures, such as lifeline bridge crossings, airports and LNG storage facilities, and has take a leadership role in code committees working to develop design code provisions for seismically isolated structures. Dr. Whittaker has co-authored, with others including Dr. Annie Kammerer, the forthcoming NUREG report on the seismic isolation of large light water reactors.

The INL team, led by Mr. Justin Coleman, will consist of individuals that have 20+ years of experience performing seismic analysis using linear and nonlinear codes. These individuals also have extensive experience performing seismic analysis for existing and new nuclear facilities. A nonlinear time domain methodology (NNSA NSRD is currently funding this effort) will be used since the standard linear, seismic soil structure interaction (SSI) approach may not provide accurate results for seismic isolation. 
Therefore it is important that this analysis be performed by individuals that have experience using nonlinear time domain codes and seismic analysis.

\section{Points of Contact:}

Justin Coleman, INL, (208) 526-4741, justin.coleman@inl.gov

Andrew Whittaker, (716) 465-7699, awhittak@,buffalo.edu

\section{References}

ASCE-4, "Seismic Analysis of Safety-Related Nuclear Structures and Commentary, DRAFT

Blue Ribbon Commission on America's Nuclear Future, Report to the Secretary of Energy, January 2012.

Coleman, Justin, "Demonstration of NonLinear Seismic Soil Structure Interaction and Applicability to New System Fragility Seismic Curves,” September 2014.

Coleman, Justin, and Sabharwall, Piyush, "Seismic Isolation Working Meeting Gap Analysis Report," September 2014.

Coleman, Justin, Spears, Bob, "Nonlinear Time Domain Seismic Soil-Structure Interaction (SSI) Methodology Development," September 2014.

Huang, Y.-N., A. S. Whittaker and N. Luco, "Performance Assessment of Conventional and BaseIsolated Nuclear Power Plants for Earthquake and Blasts Loadings," Technical Report MCEER-08-0019, State University of New York, Buffalo, October 2008.

NUREG-XXX, “Technical Considerations for Seismic Isolation of Nuclear Facilities,” DRAFT

Ostadan, F. (2006). "SASSI2000: A system for analysis of soil-structure interaction-theory manual." Department of Civil and Environmental Engineering, University of California, Berkeley, CA 
Appendix A: DOE Field Office Approval 


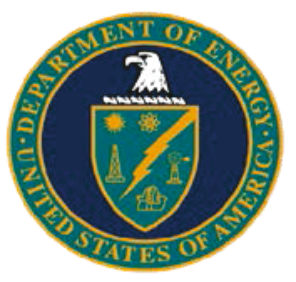

\section{Department of Energy}

Idaho Operations Office

1955 Fremont Avenue

Idaho Falls, ID 83415

February ??, 2015

NSR\&D Program Manager

HS-30/Germantown Building

U.S. Department of Energy

1000 Independence Ave., S.W.

Washington, DC 20585-1290

SUBJECT: $\quad$ Endorsement of Proposal Entitled "Mitigation of Seismic Risk at Nuclear Facilities using Seismic Isolation” for the NSR\&D Program Fiscal Year 2015 Call for Proposals.

Dear Mr. Levin,

This letter constitutes the endorsement of the proposal entitled "Mitigation of Seismic Risk at Nuclear Facilities using Seismic Isolation" for the Nuclear Safety Research and Development (NSR\&D) Program Fiscal Year 2015 Call for Proposals. The proposal, offered by Mr. Justin Coleman, P.E., of the Idaho National Laboratory (INL), is focused on developing nonlinear methodology to evaluate potential "cliff edge" effects associated with hitting a "moat wall" during an earthquake. "Moat Walls" for seismic isolation were recently incorporated into the American Society of Civil Engineers (ASCE) Standard 4, Seismic Analysis of Safety Related Nuclear Structures. As you may be aware, such recommendations often are incorporated into DOE Standards such as DOE-STD1020-2012, Natural Phenomena Hazards Analysis and Design Criteria for DOE Facilities. Additionally this research would show the potential reduction of in-structure response during a design Basis Event (DBE) at a DOE nuclear facility.

Although complimentary work is being pursued under funding from the NNSA NSR\&D program and under a CRADA with a nuclear power plant vendor, to my knowledge this proposed workscope is new work, which would add to INL's body of work on nonlinear seismic analysis, but would not duplicate any current work or outstanding proposals. This proposal has been coordinated with Mr. Brooks Weingartner, DOE-ID Technical Monitor for Seismic research and development.

Sincerely.

$/ \mathrm{s} /$

Linda S. McCoy, $\mathrm{PhD}$

Senior Scientist

DOE-Idaho 